\title{
Thermoelectric Properties of Bismuth Telluride Thin Films Electrodeposited from a Nonaqueous Solution
}

\author{
Katarina Cicvarić, * Lingcong Meng, Daniel W. Newbrook, Ruomeng Huang, Sheng Ye, Wenjian Zhang, \\ Andrew L. Hector, Gillian Reid, Philip N. Bartlett, and C. H. Kees de Groot
}

Cite This: ACS Omega 2020, 5, 14679-14688

Read Online

\section{ACCESS}

Џ Metrics \& More

Article Recommendations

Supporting Information

ABSTRACT: We report the thermoelectric properties of $\mathrm{Bi}_{2} \mathrm{Te}_{3}$ thin films electrodeposited from the weakly coordinating solvent dichloromethane $\left(\mathrm{CH}_{2} \mathrm{Cl}_{2}\right)$. It was found that the oxidation of porous films is significant, causing the degradation of its thermoelectric properties. We show that the morphology of the film can be improved drastically by applying a short initial nucleation pulse, which generates a large number of nuclei, and then growing the nuclei by pulsed electrodeposition at a much lower overpotential. This significantly reduces the oxidation of the films as smooth films have a smaller surface-to-volume ratio and are less prone to oxidation. X-ray photoelectron spectroscopy (XPS) shows that those films with $\mathrm{Te}(\mathrm{O})$ termination show a complete absence of oxygen below the surface layer. A thin film transfer process was developed using polystyrene as a carrier polymer to transfer the films from the conductive TiN to an insulating layer for thermoelectrical characterization. Temperature-dependent Seebeck measurements revealed a room-temperature coefficient of -51.7 $\mu \mathrm{V} / \mathrm{K}$ growing to nearly $-100 \mu \mathrm{V} / \mathrm{K}$ at $520^{\circ} \mathrm{C}$. The corresponding power factor reaches a value of $88.2 \mu \mathrm{W} / \mathrm{mK}^{2}$ at that temperature.

\section{INTRODUCTION}

There is a growing awareness and concern over the negative effect of greenhouse gasses on the environment, yet fossil fuel combustion still accounts for the majority of energy conversion. ${ }^{1}$ Moreover, more than $60 \%$ of energy worldwide is lost mostly in the form of waste heat. ${ }^{2}$ Thermoelectric generators could be employed to extract the waste heat and convert it into electricity, thus enabling a better use of existing energy conversion technologies ${ }^{3-5}$ or possibly thermal sensing. ${ }^{6}$

Bismuth telluride is the most efficient and most widely used thermoelectric material for low-temperature applications (up to $\left.200{ }^{\circ} \mathrm{C}\right) .^{7}$ Currently, there are a range of fabrication techniques being used for thin film fabrication, such as sputtering, chemical vapor deposition (CVD), pulsed laser deposition (PLD), molecular beam epitaxy (MBE), evaporation, and electrodeposition. In comparison to other methods for thin film fabrication, electrodeposition of such films has advantages of being relatively cost-effective as it does not require high vacuum or elevated temperatures, offers easier control over thickness and composition, and can be used for the deposition of films with thicknesses ranging from nanometers to hundreds of micrometers over a large area. Electrodeposition is also particularly well suited to the deposition on complex geometries. ${ }^{8-10}$ Electrodeposition of $\mathrm{Bi}_{2} \mathrm{Te}_{3}$ thin films has mainly been investigated in aqueous acidic solutions, such as nitric, sulfuric, or hydrochloric acid. $^{11-17}$ Several electrochemical methods have been employed for electrodeposition of $\mathrm{Bi}_{2} \mathrm{Te}_{3}$ thin films, including potentiostatic electrodeposition, ${ }^{11-14,16}$ galvanostatic electrodeposition, ${ }^{15,17}$ and pulsed electrodeposition. ${ }^{18-22}$ Nonaqueous electrolytes have a wider electrochemical window than water, allowing the investigation of more negative overpotentials, and $\mathrm{Bi}_{2} \mathrm{Te}_{3}$ thin films have also been successfully electrodeposited from these without the concomitant reduction of the solvent. Organic solvents also provide improved solubility of $\mathrm{Bi}(\mathrm{III})$ and $\mathrm{Te}(\mathrm{IV})$ salts, which are only moderately soluble in aqueous acidic media limiting the deposition rate. The use of nonaqueous solvents also widens the range of precursor salts that can be employed compared with that of aqueous media. The electrodeposition of $\mathrm{Bi}_{2} \mathrm{Te}_{3}$ thin films from nonaqueous solvents, such as dimethyl sulfoxide (DMSO), ${ }^{22}$ ethylene glycol, ${ }^{23}$ chloride-free ethylene glycol, $^{24}$ and a 1-ethyl-1-octyl-piperidinium TFSI/1-ethyl-1octyl-piperidinium bromide mixture ${ }^{25}$ have been reported in the literature.

We recently reported the potentiostatic electrodeposition of $\mathrm{Bi}_{2} \mathrm{Te}_{3}$ thin films from dichloromethane. ${ }^{26}$ Although we were successful in controlling the composition of these films by varying the deposition potential, the films were highly porous and made up of small crystallites. In this work, we show that

Received: March 31, 2020

Accepted: May 5, 2020

Published: June 11, 2020 

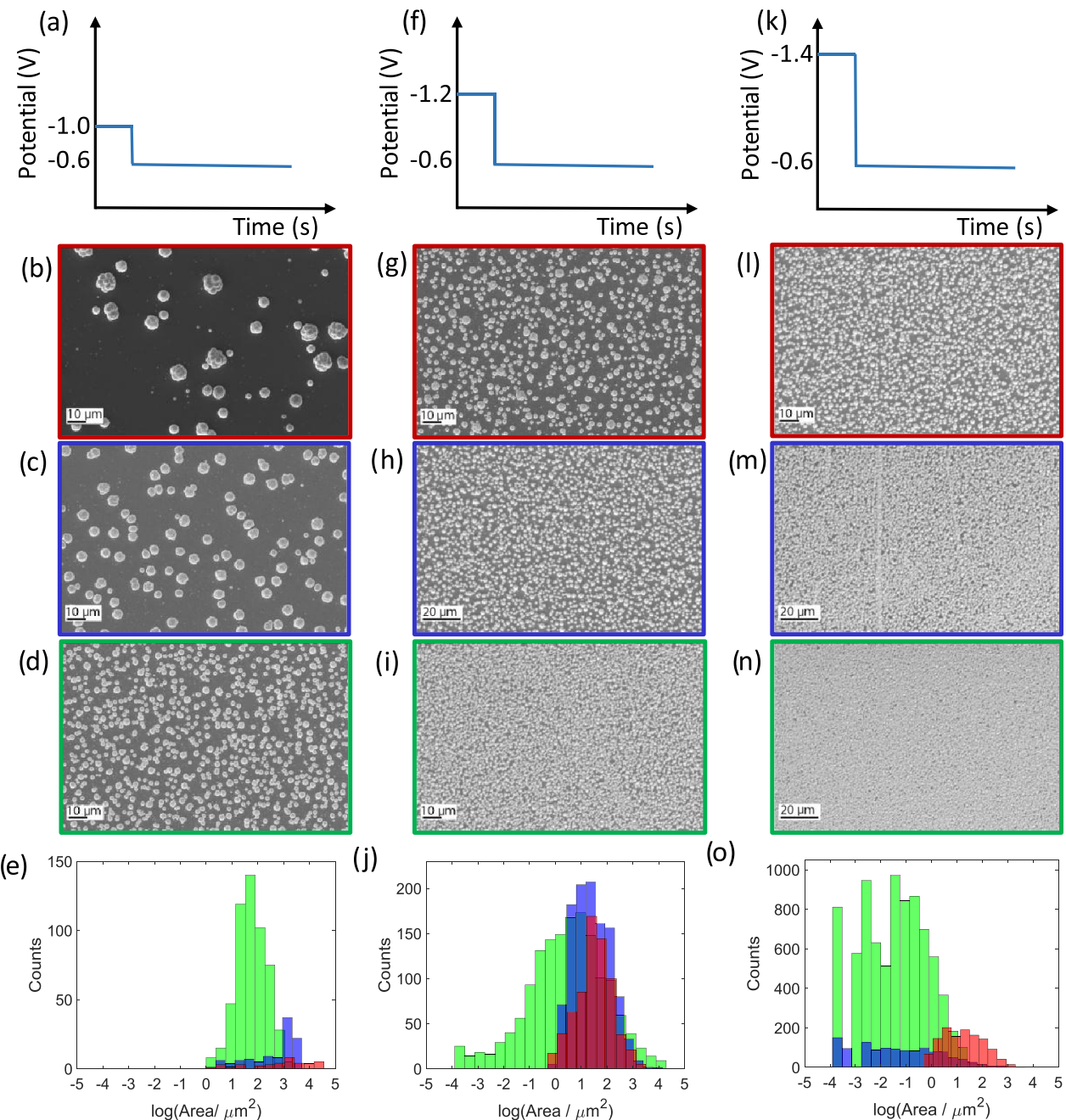

Figure 1. SEM images and histograms of electrodeposited bismuth telluride deposits grown at $E_{\text {dep }}=-0.6 \mathrm{~V}$, preceded by nucleation pulses of $E_{\text {nuc }}$ $=-1.0 \mathrm{~V}(\mathrm{a}-\mathrm{e}),-1.2 \mathrm{~V}(\mathrm{f}-\mathrm{j})$, and $-1.4 \mathrm{~V}$ vs Ag$/ \mathrm{AgCl}(\mathrm{k}-\mathrm{o})$, with nucleation pulse times $t_{\text {nuc }}=1 \mathrm{~s}($ red: $\mathrm{b}, \mathrm{g}, 1), 3 \mathrm{~s}(\mathrm{blue}: \mathrm{c}, \mathrm{h}, \mathrm{m})$, and $5 \mathrm{~s}($ green d, i, n).

using nucleation pulses and pulsed electrodeposition allows significant improvement of the film morphology and consequently the thermoelectric properties. In addition, a thin film transfer process was successfully developed allowing thermoelectric characterization of these films for the first time. The films were transferred from the TiN electrodes onto an insulating substrate $\left(\mathrm{SiO}_{2}\right)$ for subsequent electrical characterization using polystyrene as a carrier polymer. Unlike commonly used poly(methyl methacrylate), ${ }^{27}$ polystyrene has advantages of easier removal after the transfer and does not form wrinkles on the transferred films resulting in a complete transfer of the deposited film. ${ }^{28}$ Electrodeposited bismuth telluride thin films reported in the literature have so far been transferred by epoxy resin for thermoelectric measurements. ${ }^{29-31}$ However, the epoxy method leaves cracks in the transferred films visible through a microscopy and the delamination from the original substrate is not complete. Here, we show that electrodeposited bismuth telluride thin films can be completely lifted from its original substrate and transferred to an insulating substrate without cracks visible by the optical microscope nor electron microscopy.

\section{RESULTS AND DISCUSSION}

To improve the film morphology of the $\mathrm{Bi}_{2} \mathrm{Te}_{3}$ films electrodeposited using potentiostatic conditions in our previous work, ${ }^{26}$ nucleation of the film has been optimized. The $\mathrm{Bi}_{2} \mathrm{Te}_{3}$ films were grown by introducing a short initial nucleation pulse at a high overpotential, which generates a large number of nuclei, and then growing them potentiostatically or by pulsed deposition at lower overpotential. First, the early stage of film growth was investigated by applying a short nucleation pulse at high overpotentials, after which the nuclei were grown potentiostatically at $-0.6 \mathrm{~V}$ vs $\mathrm{Ag} / \mathrm{AgCl}$ with a passed charge of $-0.26 \mathrm{C}$, which would correspond to $200 \mathrm{~nm}$ thickness assuming a uniform distribution over the whole electrode area (Supporting Information, Section S3). Figure 1 shows a schematic, scanning electron microscopy (SEM) images, and histograms of the size distribution of the resulting deposited particles. The deposits were grown by applying an initial nucleation pulse of $-1.0,-1.2$, and $-1.4 \mathrm{vs} \mathrm{Ag} / \mathrm{AgCl}$ for 1,3 , or $5 \mathrm{~s}$. As can be seen from the figure, by increasing the length of the nucleation pulse, an increased coverage of the substrate surface was achieved with smaller and more uniform particles. In addition, by applying a higher initial overpotential for the same amount of time, the same effect of generating smaller, denser, and more uniform nuclei was achieved. This 

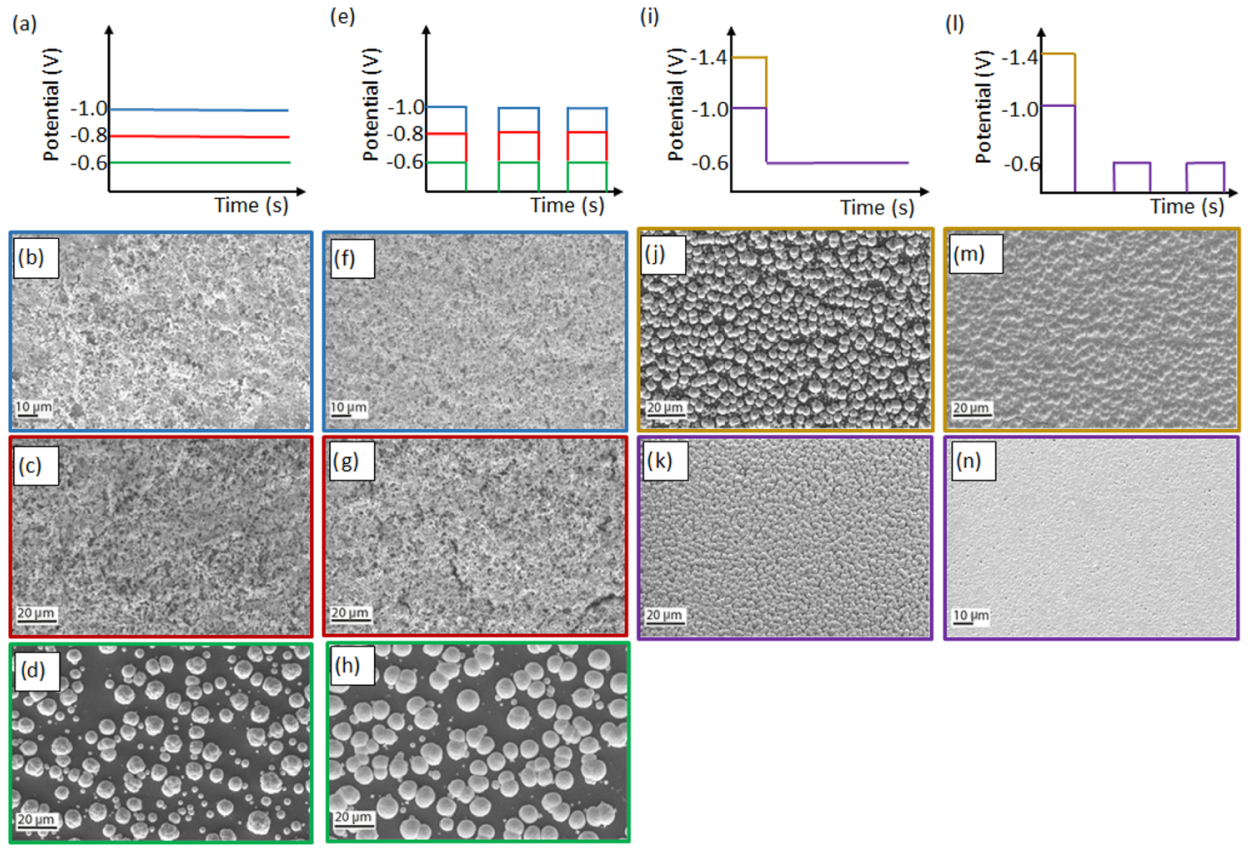

Figure 2. Schematics and SEM images of potentiostatic $(\mathrm{a}-\mathrm{d})$, pulsed $(\mathrm{e}-\mathrm{h})$, potentiostatic preceded by nucleation pulse (i-k), and pulsed preceded by nucleation pulse $(1-n)$; bismuth telluride deposition for potentials of $-1.0 \mathrm{~V}(\mathrm{~b}, \mathrm{f}),-0.8 \mathrm{~V}(\mathrm{c}, \mathrm{g}),-0.6 \mathrm{~V}(\mathrm{~d}, \mathrm{~h})$, and $-0.6 \mathrm{~V}$ preceded by nucleation pulses of $-1.4 \mathrm{~V}(\mathrm{j}, \mathrm{m})$ and $-1.0 \mathrm{~V}(\mathrm{k}, \mathrm{n}) \mathrm{vs} \mathrm{Ag} / \mathrm{AgCl} . t_{\mathrm{on}}=5 \mathrm{~s}$ and $t_{\text {off }}=10 \mathrm{~s}$ for all pulsed electrodepositions.

Table 1. Elemental Composition Showing Bi-to-Te Atomic Ratios and Atomic Percentage of O Measured on Three Different Areas of the Film Showing Average Values and Standard Deviation ${ }^{a}$

\begin{tabular}{llcc}
\multicolumn{1}{c}{ method } & potential vs $\mathrm{Ag} / \mathrm{AgCl} / \mathrm{V}$ & $\mathrm{Bi}: \mathrm{Te} \pm$ stdev & $\%$ atomic $\mathrm{O} \pm$ stdev \\
potentiostatic & $E_{\text {dep }}=-1.0$ & $0.5 \pm 0.01$ & $32.4 \pm 1.08$ \\
potentiostatic & $E_{\text {dep }}=-0.8$ & $0.5 \pm 0.01$ & $38.0 \pm 0.25$ \\
potentiostatic & $E_{\text {dep }}=-0.6$ & $0.8 \pm 0.03$ & $13.1 \pm 0.46$ \\
pulsed & $E_{\text {dep }}=-1.0$ & $0.7 \pm 0.03$ & $33.8 \pm 1.83$ \\
pulsed & $E_{\text {dep }}=-0.8$ & $0.6 \pm 0.02$ & $17.8 \pm 4.41$ \\
pulsed & $E_{\text {dep }}=-0.6$ & $0.8 \pm 0.05$ & $13.8 \pm 3.73$ \\
potentiostatic with nucleation pulse & $E_{\text {dep }}=-0.6, E_{\text {nuc }}=-1.4$ & $0.6 \pm 0.04$ & $4.4 \pm 0.26$ \\
potentiostatic with nucleation pulse & $E_{\text {dep }}=-0.6, E_{\text {nuc }}=-1.0$ & $0.9 \pm 0.01$ & $26.0 \pm 1.44$ \\
pulsed with nucleation pulse & $E_{\text {dep }}=-0.6, E_{\text {nuc }}=-1.4$ & $0.5 \pm 0.02$ & $0.3 \pm 0.50$ \\
pulsed with nucleation pulse & $E_{\text {dep }}=-0.6, E_{\text {nuc }}=-1.0$ & $0.7 \pm 0.01$ & $6.5 \pm 0.95$
\end{tabular}

${ }^{a}$ All films are electrodeposited from an electrolyte containing $2.25 \mathrm{mM}\left[\mathrm{N}^{n} \mathrm{Bu}_{4}\right]\left[\mathrm{BiCl}_{4}\right], 3 \mathrm{mM}\left[\mathrm{N}^{n} \mathrm{Bu}_{4}\right]_{2}\left[\mathrm{TeCl}_{6}\right]$, and $0.1 \mathrm{M}\left[\mathrm{N}^{n} \mathrm{Bu} u_{4}\right] \mathrm{Cl}$ by different methods. $t_{\mathrm{on}}=5 \mathrm{~s}$ and $t_{\mathrm{off}}=10 \mathrm{~s}$ for all pulsed depositions.

indicates progressive nucleation, meaning that the nucleation process is slow and new nuclei continue to form during the deposition, while those already formed continue to grow. Hence, by applying a potential of $-1.4 \mathrm{~V}$ for $5 \mathrm{~s}$ and then growing the nuclei at $-0.6 \mathrm{~V}$ vs $\mathrm{Ag} / \mathrm{AgCl}$, almost full coverage of uniform, densely packed particles was obtained. Image ${ }^{32}$ was used to extract the number and the areal size of the electrodeposited crystallites plotted as histograms. The deposits formed with nucleation potentials of $-1.0 \mathrm{~V}$ for $5 \mathrm{~s}$ and $-1.4 \mathrm{~V}$ for $5 \mathrm{~s}$ show particle counts of at least a factor of 10 higher than the deposits formed with shorter pulses at lower potential. This corresponds to a volume particle size reduction of the same factor. These nucleation pulse values were therefore selected for further investigation and optimization of bismuth telluride thin film growth.

Figure 2 shows SEM images of films grown potentiostatically (Figure $2 \mathrm{~b}-\mathrm{d}$ ), by pulsed electrodeposition (Figure $2 \mathrm{f}-\mathrm{h}$ ), potentiostatically preceded by a nucleation pulse (Figure $2 \mathrm{j}, \mathrm{k}$ ), and by pulsed deposition preceded by a nucleation pulse
(Figure $2 \mathrm{~m}, \mathrm{n}$ ). Growing films by pulsed electrodeposition yields somewhat smoother films with improved composition repeatability compared to those grown potentiostatically. For the pulsed deposition during the off-time, when no current passes, the concentrations of $\mathrm{Bi}$ and $\mathrm{Te}$ species at the electrode surface replenish by diffusion. As a result, under pulsed conditions, the composition of the films can be better controlled due to the replenishment of the reactants in each cycle. ${ }^{19}$ The duration of on- and off-pulses during pulsed electrodeposition was optimized to $5 \mathrm{~s}$ on-time and $10 \mathrm{~s}$ offtime. As can be seen from Figure 2, both the films grown potentiostatically and by pulsed electrodeposition at potentials of $-1.0 \mathrm{~V}$ (Figure $2 \mathrm{~b}, \mathrm{f}$ ) and $-0.8 \mathrm{~V}$ (Figure $2 \mathrm{c}, \mathrm{g}$ ) vs $\mathrm{Ag} / \mathrm{AgCl}$ exhibit similar porous but continuous morphologies. The thickness of the films is estimated to be $1 \mu \mathrm{m}$ from the total charge passed of $-1.3 \mathrm{C}$ for potentiostatically grown films. For the films grown by pulsed deposition, the estimated thickness is $950 \mathrm{~nm}$ from the charge passed of $-1.2 \mathrm{C}$ and $1.4 \mu \mathrm{m}$ from the charge passed of $-1.8 \mathrm{C}$ for films grown at -1.0 and -0.8 
Table 2. Lattice Parameters and Crystallite Sizes for Different Bismuth Telluride Films from X-ray Diffraction Data Obtained Using the PDXL Programme

\begin{tabular}{|c|c|c|c|c|}
\hline method & potential & $a(\AA)$ & $c(\AA)$ & crystallite size $(\AA)$ \\
\hline potentiostatic & $E_{\mathrm{dep}}=-1.0 \mathrm{~V}$ & $4.16(10)$ & $30(3)$ & 18 \\
\hline pulsed & $E_{\mathrm{dep}}=-1.0 \mathrm{~V}$ & $4.1(4)$ & $30.0(19)$ & 27 \\
\hline pulsed & $E_{\mathrm{dep}}=-0.6 \mathrm{~V}$ & $4.48(6)$ & $28.8(5)$ & 35 \\
\hline pulsed with an initial nucleation pulse & $E_{\text {dep }}=-0.6 \mathrm{~V}, E_{\mathrm{nuc}}=-1.0 \mathrm{~V}$ & $4.35(8)$ & $29.2(5)$ & 41 \\
\hline pulsed with an initial nucleation pulse & $E_{\text {dep }}=-0.6 \mathrm{~V}, E_{\text {nuc }}=-1.4 \mathrm{~V}$ & $4.33(4)$ & $30.0(5)$ & 36 \\
\hline
\end{tabular}

$\mathrm{V}$ vs $\mathrm{Ag} / \mathrm{AgCl}$, respectively. However, when growing films potentiostatically and by pulsed electrodeposition at a lower potential of $-0.6 \mathrm{~V}$ vs $\mathrm{Ag} / \mathrm{AgCl}$, a significant change in morphology was observed (Figure 2d,h). The resulting deposits in this case are not films but rather comprise discontinuous islands. Furthermore, the deposits obtained by pulsed electrodeposition are smoother, slightly larger, and more uniform in size than the deposits obtained potentiostatically. The calculated thickness of the uniform film over the given area grown potentiostatically is 1 , and $1.8 \mu \mathrm{m}$ from a charge of $-2.3 \mathrm{C}$ for the film grown by pulsed deposition at $-0.6 \mathrm{~V}$ vs $\mathrm{Ag} / \mathrm{AgCl}$. Table 1 gives the average and standard deviation of Bi-to-Te ratios and atomic percentage of oxygen measured by energy-dispersive X-ray (EDX) elemental analysis on three different areas of the films. The presence of $\mathrm{Bi}$ and $\mathrm{Te}$ confirms the deposition of bismuth telluride, with slight variation of the average Bi-to-Te ratios from stoichiometric composition (0.7) when applying different potentials and deposition methods. Furthermore, the small standard deviation $(\leq 0.05)$ in Bi-to-Te ratios obtained in all films proves excellent composition uniformity regardless of the method. The $\mathrm{O}$ signal most probably indicates oxidation of the bismuth telluride films.

The films grown potentiostatically and by pulsed electrodeposition preceded by a nucleation pulse are compared. As can be seen in Figure 2, considerable change in morphology is noticeable between films grown potentiostatically (Figure $2 \mathrm{j}, \mathrm{k}$ ) and by pulsed electrodeposition (Figure 2m,n) after introducing an initial nucleation pulse at higher potential. The films grown by pulsed electrodeposition are compact, continuous, and smooth, while those grown potentiostatically are discontinuous. The calculated thickness of the deposits electrodeposited potentiostatically is $1 \mu \mathrm{m}$. For the films grown by pulsed electrodeposition, the calculated thickness from the passed charge of $-0.6 \mathrm{C}$ is $500 \mathrm{~nm}$ and $1.4 \mu \mathrm{m}$ for a charge of $-1.8 \mathrm{C}$ for nucleation potentials of -1.0 and $-1.4 \mathrm{~V}$ vs $\mathrm{Ag} /$ $\mathrm{AgCl}$, respectively. Cross-sectional SEM images of the films electrodeposited by pulsed electrodeposition preceded by a nucleation pulse reveal the actual thicknesses of $675 \mathrm{~nm}$ and 2 $\mu \mathrm{m}$ for nucleation pulses of -1.0 and $-1.4 \mathrm{~V}$ vs $\mathrm{Ag} / \mathrm{AgCl}$, respectively. The $35 \%$ discrepancy between the calculated and measured values is possibly due to the residual porosity in the films. On the other hand, the calculated thickness of the porous film electrodeposited potentiostatically at $-1 \mathrm{~V}$ vs $\mathrm{Ag} /$ $\mathrm{AgCl}$ is $1 \mu \mathrm{m}$, while the cross-sectional SEM reveals a thickness of $4.5 \mu \mathrm{m}$. This large factor of 4 discrepancy between the theoretical and measured values is definitely due to the porosity of the film. Furthermore, as shown in Table 2, the oxygen content is significantly lower in films grown by pulsed deposition preceded by a nucleation pulse compared to that of films obtained by other methods. This is probably due to the compact and smooth surface morphology of these films that have a smaller exposed surface area than that of the porous films and are therefore less prone to atmospheric oxidation.

Crystal Structure of Electrodeposited Bismuth Telluride Films. Figure 3 shows the diffraction patterns of

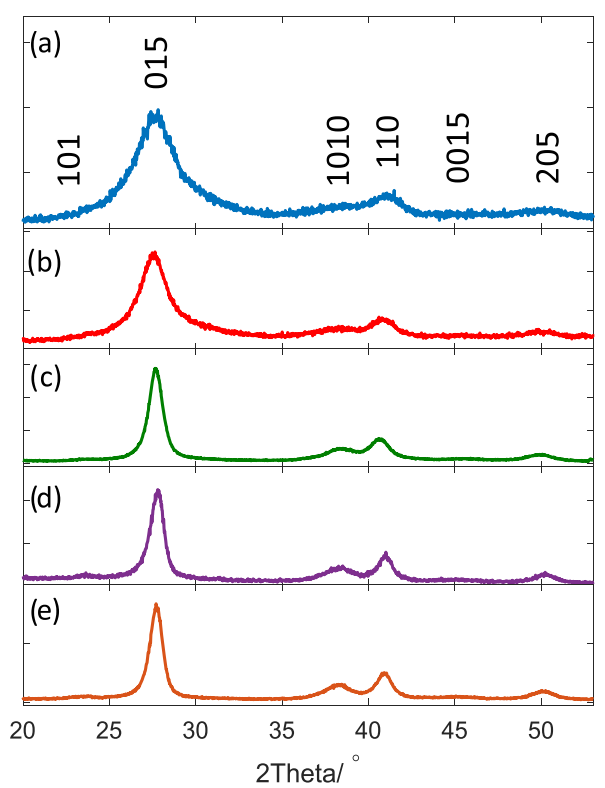

Figure 3. X-ray diffraction (XRD) patterns collected on bismuth telluride films electrodeposited potentiostatically at $-1.0 \mathrm{~V}$ (a), by pulsed deposition at $-1.0 \mathrm{~V}(\mathrm{~b})$, by pulsed deposition at $-0.6 \mathrm{~V}$ without an initial nucleation pulse (c), and by pulsed deposition at $-0.6 \mathrm{~V}$ with an initial nucleation pulse at $-1.0 \mathrm{~V}(\mathrm{~d})$ and $-1.4 \mathrm{~V}(\mathrm{e})$ vs $\mathrm{Ag} / \mathrm{AgCl} . t_{\text {on }}=5 \mathrm{~s}$ and $t_{\text {off }}=10 \mathrm{~s}$ for all pulsed depositions.

bismuth telluride films electrodeposited onto TiN electrodes; there are peaks at $2 \theta$ angles of 23.64, 27.71, 38.31, 40.97, 45.10 , and $50.05^{\circ}$. The X-ray diffraction analysis of bismuth telluride thin films electrodeposited by different methods shows that the diffraction patterns are very similar regardless of the method. The peaks can be attributed to trigonal $\mathrm{Bi}_{2} \mathrm{Te}_{3}$, although the presence of elemental $\mathrm{Te}$ cannot be completely discounted as they share many reflection positions. The results were fitted against the literature pattern ${ }^{33}$ and show good agreement. The 015 reflection at $27.7^{\circ}$ is of the highest intensity for all of the films, and its width indicates crystallite size with the broadest indicating the smallest and the narrowest indicating the largest crystallite size. This relationship between the peak width and the crystallite size is given by the Scherrer equation $\tau=\frac{K \lambda}{\beta \cos \theta}$

Crystallite sizes of bismuth telluride films electrodeposited by different methods were obtained using the PDXL package and are shown in Table 2. The smallest crystallite size was obtained for films electrodeposited potentiostatically at $-1 \mathrm{~V}$ vs $\mathrm{Ag} / \mathrm{AgCl}$, which corresponds to the highest nucleation rate. 
(a)

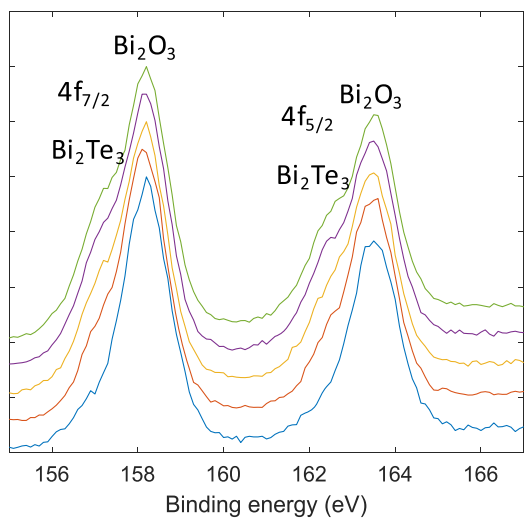

(c)

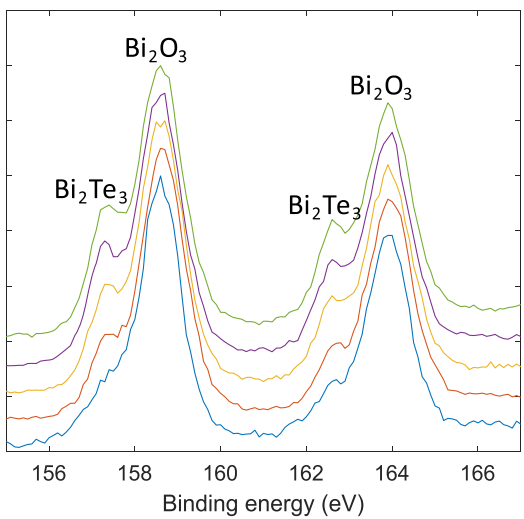

(e)

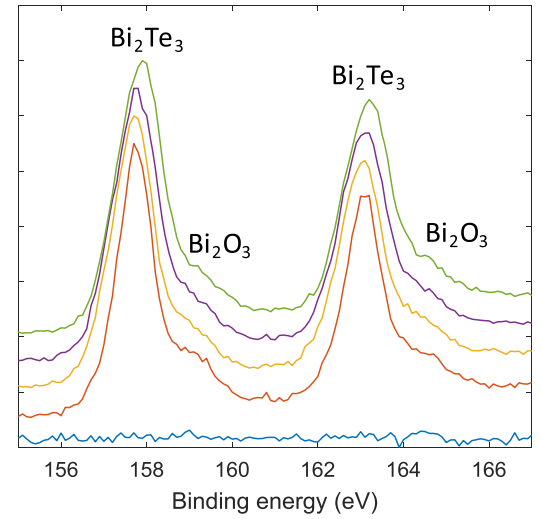

(b)

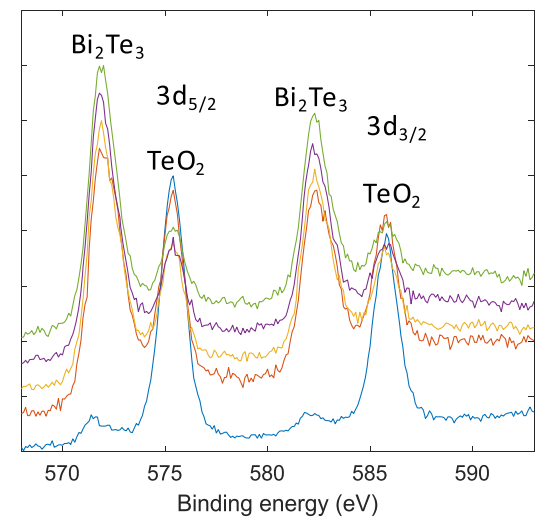

(d)

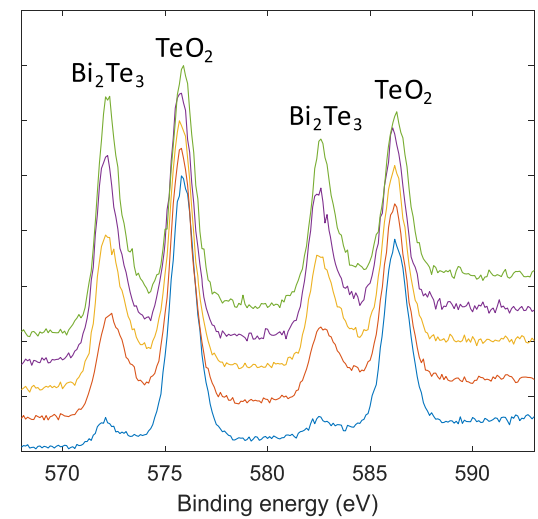

(f)

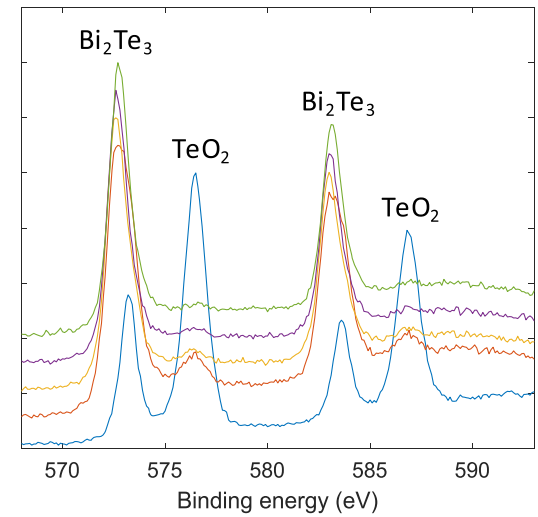

Figure 4. Bi $4 \mathrm{f}$ (left) and Te 3d (right) regions of the XPS spectra for bismuth telluride films electrodeposited: by pulsed electrodeposition at -1.0 $\mathrm{V}(\mathrm{a}, \mathrm{b})$, pulsed electrodeposition at $-0.6 \mathrm{~V}$ preceded by a nucleation pulse at $-1.0 \mathrm{~V}(\mathrm{c}, \mathrm{d})$, and a nucleation pulse at $-1.4 \mathrm{~V}(\mathrm{e}, \mathrm{f})$. Blue: surface prior to etching, orange: after $60 \mathrm{~s}$ of etching, yellow: after $120 \mathrm{~s}$ of etching, purple: after $180 \mathrm{~s}$ of etching, and green: after $240 \mathrm{~s}$ of etching.

The films obtained by pulsed electrodeposition at the same potential exhibit larger crystallite size. Growing films at an even lower overpotential of $-0.6 \mathrm{~V}$ vs $\mathrm{Ag} / \mathrm{AgCl}$ by pulsed electrodeposition gave a much larger crystallite size due to the lower nucleation rate at the lower overpotential. The films electrodeposited by pulsed electrodeposition at a lower overpotential of $-0.6 \mathrm{~V}$ vs $\mathrm{Ag} / \mathrm{AgCl}$ preceded by a nucleation pulse also possess a larger crystallite size, comparable to those grown without a nucleation pulse. Thus, it is possible to alter the crystallite sizes of bismuth telluride films, which, in turn, could have a beneficial effect on the electrical conductivity and therefore the thermoelectric properties of the films.

Oxidation of Bismuth Telluride Films. Surface oxidation of electrodeposited bismuth telluride films was investigated by X-ray photoelectron spectroscopy (XPS). XPS measurements were carried out on films electrodeposited by pulsed electrodeposition either with or without an initial nucleation pulse, as shown in Figure 4. The samples were taken out of the solution after the deposition and transferred onto an insulating substrate within a couple of days before the measurements were taken. The scans show the $\mathrm{Bi} 4 \mathrm{f}$ and $\mathrm{Te} 3 \mathrm{~d}$ doublets. For each sample, the first measurement was taken at the surface layer followed by four cycles of etching with Ar ions for $60 \mathrm{~s}$ to expose deeper layers in the bulk of the material. The etching rate is approximately $0.5 \mathrm{~nm} / \mathrm{s}$, meaning that after each etching cycle measurements were taken $30 \mathrm{~nm}$ deeper in the bulk of the material. The reference for XPS spectra analysis is the C $1 \mathrm{~s}$ peak at a binding energy of $284.8 \mathrm{eV}$. The $\mathrm{Bi} 4 \mathrm{f}_{7 / 2}$ peak is composed of two contributions at $157.4 \pm 0.3$ and $158.6 \pm 0.4$ $\mathrm{eV}$ corresponding to $\mathrm{Bi}$ in $\mathrm{Bi}_{2} \mathrm{Te}_{3}$ and $\mathrm{Bi}$ in $\mathrm{Bi}_{2} \mathrm{O}_{3}$, respectively, with the associated $\mathrm{Bi} 4 \mathrm{f}_{5 / 2}$ peaks at $162.8 \pm 0.3$ and $163.9 \pm$ $0.5 \mathrm{eV}^{34-37}$ The two peaks for $\mathrm{Bi}-\mathrm{Te}$ and $\mathrm{Bi}-\mathrm{O}$ are observed 


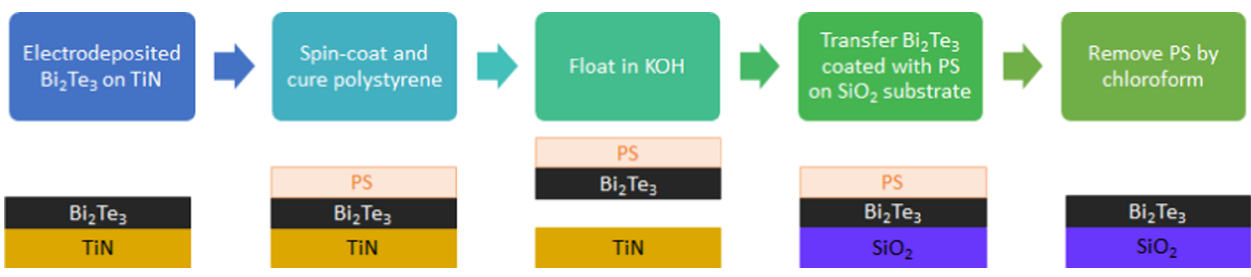

Figure 5. Schematic of the polystyrene-based process used to transfer $\mathrm{Bi}_{2} \mathrm{Te}_{3}$ films electrodeposited on $\mathrm{TiN}$ to an insulating $\mathrm{SiO}_{2}$ substrate.

due to spin-orbital splitting of the f-orbital into $f_{5 / 2}$ and $f_{7 / 2}$ components with an area ratio of $3 / 4$. In our cases, the free fitted area ratio is 0.79 for both $\mathrm{Bi}-\mathrm{Te}$ and $\mathrm{Bi}-\mathrm{O}$. The Te has contributions of $3 \mathrm{~d}_{5 / 2}$ at $572.1 \pm 0.4$ and $575.8 \pm 0.5 \mathrm{eV}$ corresponding to $\mathrm{Bi}_{2} \mathrm{Te}_{3}$ and $\mathrm{TeO}_{2}$, respectively. The contributions of $3 \mathrm{~d}_{3 / 2}$ are at $582.6 \pm 0.4 \mathrm{eV}$ and $586.2 \pm 0.5$ $e \mathrm{e}^{34-37}$ The free fitted area ratio of the $\mathrm{d}_{5 / 2}$ and $\mathrm{d}_{3 / 2}$ doublets is 0.69 , close to a theoretical value of $2 / 3$.

The $\mathrm{Bi}$ peaks in films electrodeposited by pulsed electrodeposition show that the $\mathrm{Bi}_{2} \mathrm{O}_{3}$ peaks have higher intensities than $\mathrm{Bi}_{2} \mathrm{Te}_{3}$ even in deeper layers of the material, although the $\mathrm{Bi}_{2} \mathrm{Te}_{3}$ peak intensities increase slightly as deeper layers are exposed (Figure 4a). The more compact and smoother film electrodeposited by pulsed electrodeposition with an initial nucleation pulse at $-1.0 \mathrm{~V}$ shows a similar trend (Figure $4 \mathrm{c}$ ). For both films, the Te on the surface is mainly in the form of $\mathrm{TeO}_{2}$, while after exposure of the deeper layers $\mathrm{Te}$ in the form of $\mathrm{Bi}_{2} \mathrm{Te}_{3}$ is more prominent although a significant contribution from $\mathrm{TeO}_{2}$ is still present (Figure 4b,d).

In contrast, in the case of the film electrodeposited with an initial nucleation pulse at $-1.4 \mathrm{~V}$, there is no $\mathrm{Bi}$ at all in the surface layer, and the deeper layers are composed of $\mathrm{Bi}_{2} \mathrm{Te}_{3}$ with an almost negligible amounts of $\mathrm{Bi}_{2} \mathrm{O}_{3}$ (Figure 4e). The Te spectra confirm the $\mathrm{Bi}$ spectral observation for this film. Here, the surface layer is predominantly $\mathrm{Te}$ in the form of $\mathrm{TeO}_{2}$ with a significant amount of $\mathrm{Bi}_{2} \mathrm{Te}_{3}$, and the deeper layers are in the form of $\mathrm{Bi}_{2} \mathrm{Te}_{3}$ with a negligible amount of oxidized $\mathrm{Te}$ (Figure 4f). The film possesses Te termination, which is mainly oxidized and prevents further oxidation of the underlying film. These data are in full agreement with the EDX data, which showed 33.8 and $6.5 \%$ of oxygen for the former two films, and $0.3 \%$ for the film with the initial nucleation pulse at $-1.4 \mathrm{~V}$ followed by the pulsed electrodeposition at $-0.6 \mathrm{~V}$. Music et al. ${ }^{38}$ also observed that Te termination of bismuth telluride slows down the oxidation of $\mathrm{Bi}_{2} \mathrm{Te}_{3}$. After the last etching cycle, the measurements were taken about $120 \mathrm{~nm}$ into the bulk of the material, still revealing at least some oxidation in the bulk as a result of oxygen diffusion. Although it was reported that $\mathrm{Bi}_{2} \mathrm{Te}_{3}$ thin films grown by molecular beam epitaxy are stable and surface oxidation occurs on the time scale of months, ${ }^{39}$ in the case of porous films the oxidation is significant and can be reduced by decreasing the surface-tovolume ratio and, more importantly, by obtaining $\mathrm{Te}$ termination on the surface.

Thin Film Transfer. The separation of the bismuth telluride film was achieved in $\mathrm{KOH}$ solution, as $\mathrm{KOH}$ acts on the interface between the substrate and lifting the film. The separation then gradually spreads due to capillary wetting. Figure 6a,b shows images taken under the optical microscope of a bismuth telluride film electrodeposited onto a TiN electrode and a bismuth telluride film transferred to the $\mathrm{SiO}_{2}$ substrate, respectively. Although polystyrene residues are visible on the film after the transfer, the transfer process is (a)
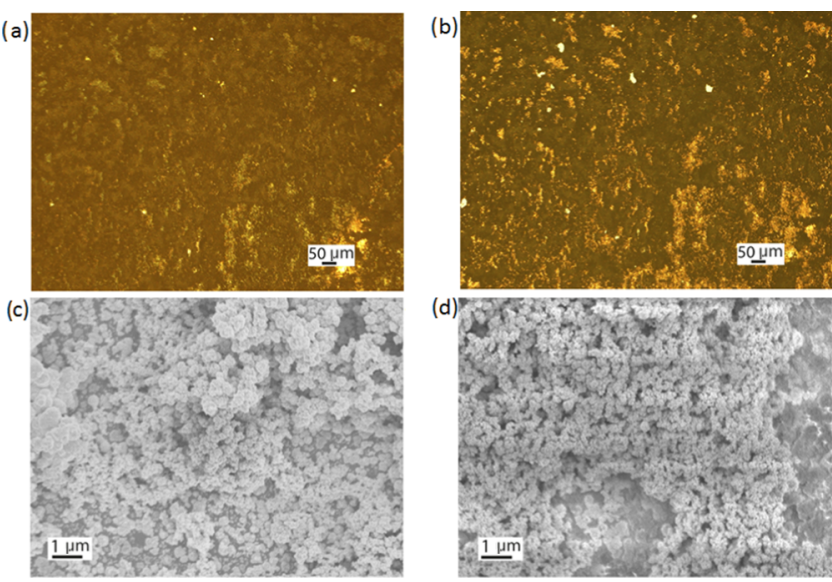

Figure 6. Optical images of a bismuth telluride film electrodeposited on a TiN electrode (a) before the transfer and (b) after transfer to the $\mathrm{SiO}_{2}$ substrate. SEM images of a bismuth telluride film (c) before and (d) after the transfer.

complete and the transferred films are uniform without wrinkles or cracks (Figure 6b). Figure 6c,d shows SEM images of the bismuth telluride film before and after transfer; they also show that there are no cracks in the film after transfer, demonstrating the integrity of the transfer process.

\section{THERMOELECTRIC CHARACTERIZATION}

Thermoelectric characterization was conducted on the film electrodeposited by pulsed electrodeposition at $-0.6 \mathrm{~V}$ vs $\mathrm{Ag} /$ $\mathrm{AgCl}$ for on-time $5 \mathrm{~s}$ and off-time $10 \mathrm{~s}$ with an initial nucleation pulse of $-1.0 \mathrm{~V}$ vs $\mathrm{Ag} / \mathrm{AgCl}$ for $5 \mathrm{~s}$. The electrodeposited film is n-type with a charge carrier concentration of $(2.8 \pm 1.2) \times 10^{20} \mathrm{~cm}^{-3}$ and a resistivity of $15.9 \mathrm{~m} \Omega \mathrm{cm}$ at room temperature obtained from Hall measurements. The resistivity decreases with increasing temperature (Figure 7a), meaning that the electrodeposited bismuth telluride film exhibits semiconducting behavior with further thermal activation at higher temperature. The film exhibits a Seebeck coefficient of $-51.7 \mu \mathrm{V} / \mathrm{K}$ at $300 \mathrm{~K}$, which increases with temperature reaching a value of $-96.6 \mu \mathrm{V} / \mathrm{K}$ at $520 \mathrm{~K}$ (Figure 7a). The decrease in Seebeck coefficient after $520 \mathrm{~K}$ is due to the bipolar effect. At the temperature of $\sim 500$ $\mathrm{K}$, electrons from the valence band are elevated into the conduction band. This gives rise to minority carriers (in this case, holes), traveling in the opposite direction. The two types of carriers have opposite signs of Seebeck coefficient canceling each other and therefore decreasing the material's Seebeck coefficient with further temperature increase. The power factor is defined as $S^{2} \sigma$, meaning that it depends only on the Seebeck coefficient and the electrical conductivity of the material. Figure $7 \mathrm{~b}$ shows the power factor of the thin film as a function of temperature, showing that the power factor increases with increasing temperature reaching a value of $88.2 \mu \mathrm{W} / \mathrm{mK}^{2}$ at 

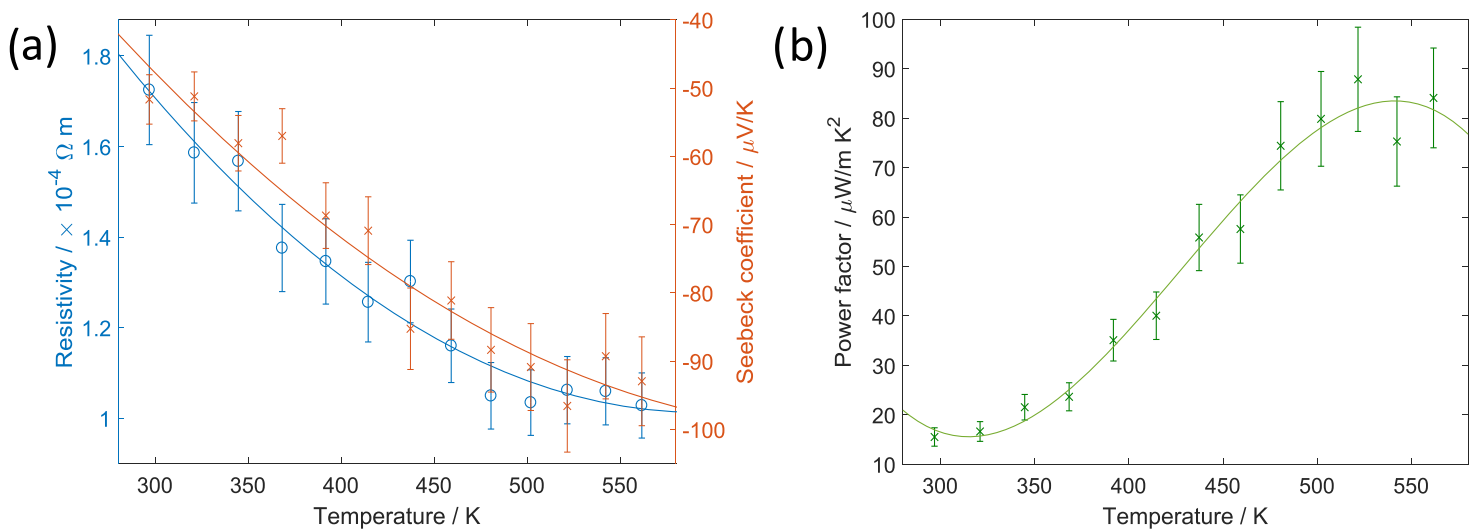

Figure 7. Dependence of (a) resistivity and Seebeck coefficient, and (b) power factor with temperature for the bismuth telluride film electrodeposited by pulsed electrodeposition at $-0.6 \mathrm{~V} \mathrm{vs} \mathrm{Ag/AgCl}$ for on-time $5 \mathrm{~s}$ and off-time $10 \mathrm{~s}$ with an initial nucleation pulse to $-1 \mathrm{~V}$ vs $\mathrm{Ag} /$ $\mathrm{AgCl}$ for $5 \mathrm{~s}$. Error bars are based on the tool manufacturer's information. Lines are guides to the eye.

$520 \mathrm{~K}$, in accordance with the increase in Seebeck coefficient. The porous films obtained potentiostatically or by pulsed electrodeposition are insulating probably due to oxidation of the films as a result of high surface-to-volume ratio, and no Seebeck or resistivity data could be extracted. There is a range of values for Seebeck coefficient and resistivity of electrodeposited bismuth telluride thin films reported in the literature. However, we compare our data to that from the MartinGonzalez group ${ }^{19,21,40}$ who carried out an extensive study on electrodeposition of bismuth telluride thin films from an aqueous solution. The obtained carrier concentration and the Seebeck coefficient values of our electrodeposited bismuth telluride films are close to the reported data; however, the resistivity value is higher than the reported ones. Manzano et al. $^{21}$ reported a carrier concentration of $3.2 \times 10^{20} \mathrm{~cm}^{-3}$ and a Seebeck coefficient of $-58 \mu \mathrm{V} / \mathrm{K}$, which correspond to our measured values of $(2.8 \pm 1.2) \times 10^{20} \mathrm{~cm}^{-3}$ for carrier concentration and $-51.7 \mu \mathrm{V} / \mathrm{K}$ for Seebeck coefficient. The reported resistivity is $1.5 \mathrm{~m} \Omega \mathrm{cm}$, lower than our measured value of $15.9 \mathrm{~m} \Omega \mathrm{cm}$.

\section{CONCLUSIONS}

Bismuth telluride films were fabricated by potentiostatic and pulsed electrodeposition with or without a preceding nucleation pulse from dichloromethane, using $\left[\mathrm{N}^{n} \mathrm{Bu}_{4}\right]\left[\mathrm{BiCl}_{4}\right]$ and $\left[\mathrm{N}^{n} \mathrm{Bu}_{4}\right]_{2}\left[\mathrm{TeCl}_{6}\right]$ as the $\mathrm{Bi}$ and $\mathrm{Te}$ precursors. The composition repeatability between replicate samples was significantly improved in films produced by pulsed electrodeposition compared to those obtained potentiostatically. In addition, somewhat smoother films were obtained by pulsed electrodeposition; however, both methods yield either porous or discontinuous films, which are unsuitable for thermoelectric applications. Nucleation of the films was optimized by applying an initial nucleation pulse at high overpotential followed by growth of the films either potentiostatically or by pulsed electrodeposition at lower overpotential. The films grown potentiostatically preceded by a nucleation pulse are discontinuous, while those grown by pulsed electrodeposition preceded by a nucleation pulse are continuous, compact, and smooth. XPS measurements reveal that the porous films are prone to oxidation, possibly due to their high surface-tovolume ratio, while the smooth and compact films are significantly less oxidized. Moreover, it was found that if the smooth and compact films were Te-terminated the oxidation was suppressed. The effect of oxidation was also observed in EDX compositional analysis, where the oxygen content dropped considerably for smooth films obtained by pulsed electrodeposition preceded by a nucleation pulse as compared to that of the porous films. The XRD measurements show that films grown at a lower overpotential have larger crystallite sizes, and the films grown at a lower overpotential either with or without a preceding nucleation pulse exhibit similar crystallite sizes. To perform electrical measurements, the films were transferred using polystyrene as a carrier polymer. The transfer process was complete, and the films had no wrinkles or cracks after transfer. The porous films produced by potentiostatic and pulsed electrodeposition were found to be insulating most probably due to their high surface area prone to oxidation, which degrades the thermoelectric properties of these films. The compact and smooth film produced by pulsed electrodeposition at $-0.6 \mathrm{~V}$ preceded by a nucleation pulse at $-1.0 \mathrm{~V}$ vs $\mathrm{Ag} / \mathrm{AgCl}$ exhibits semiconducting behavior with the resistivity of the film decreasing with increasing temperature. The temperature-dependent Seebeck coefficient measurements show a Seebeck coefficient of $-51.7 \mu \mathrm{V} / \mathrm{K}$ at room temperature, reaching $-96.6 \mu \mathrm{V} / \mathrm{K}$ at $520 \mathrm{~K}$. The power factor reaches a value of $88.2 \mu \mathrm{W} / \mathrm{mK}^{2}$ at $520 \mathrm{~K}$.

\section{MATERIALS AND METHODS}

Electrodeposition. Electrolytes were prepared in anhydrous $\mathrm{CH}_{2} \mathrm{Cl}_{2}$ (Sigma-Aldrich, 95\%) and dried by refluxing with $\mathrm{CaH}_{2}$ (followed by distillation and then stored in the glovebox; the water content in the dried $\mathrm{CH}_{2} \mathrm{Cl}_{2}$ was ca. 18 $\mathrm{ppm}$ ) with the addition of $0.1 \mathrm{M}\left[\mathrm{N}^{n} \mathrm{Bu}_{4}\right] \mathrm{Cl}$ (Sigma-Aldrich, $\geq 99.0 \%$, as-received) as the supporting electrolyte. The $\mathrm{Bi}$ and Te precursors $\left(\left[\mathrm{N}^{n} \mathrm{Bu}_{4}\right]\left[\mathrm{BiCl}_{4}\right]\right.$ and $\left.\left[\mathrm{N}^{n} \mathrm{Bu}_{4}\right]_{2}\left[\mathrm{TeCl}_{6}\right]\right)$ were synthesized as described in the literature. ${ }^{41}$

The cyclic voltammetry (Supporting Information, Section S1) and electrodeposition experiments were carried out in a recirculating glovebox (Belle Technology, U.K.) using an Autolab potentiostat ( $\mu$ AUT70706). The experiments were carried out in an electrolyte containing $2.25 \mathrm{mM}\left[\mathrm{N}^{n} \mathrm{Bu}_{4}\right]$ $\left[\mathrm{BiCl}_{4}\right], 3 \mathrm{mM}\left[\mathrm{N}^{n} \mathrm{Bu}_{4}\right]_{2}\left[\mathrm{TeCl}_{6}\right]$, and $0.1 \mathrm{M}\left[\mathrm{N}^{n} \mathrm{Bu} 4\right] \mathrm{Cl}$ in anhydrous $\mathrm{CH}_{2} \mathrm{Cl}_{2}$ using a three-electrode system with a $1 \mathrm{~cm}$ diameter $\mathrm{Pt}$ coin as the counter electrode, and an $\mathrm{Ag} / \mathrm{AgCl}$ $\left(0.1 \mathrm{M}\left[\mathrm{N}^{n} \mathrm{Bu}_{4}\right] \mathrm{Cl}\right.$ in anhydrous $\mathrm{CH}_{2} \mathrm{Cl}_{2}$ ) as the reference electrode. As the working electrode, either a $3 \mathrm{~mm}$ diameter glass-sealed glassy carbon (GC, Sigradur G, HTW, Germany) 
or $7 \times 11 \mathrm{~mm}$ titanium nitride $(\mathrm{TiN})$ electrode was used. The glass-sealed GC electrode was used for precursor characterization experiments. It was cleaned by polishing with alumina powder $(1 \mu \mathrm{m}$ and $0.05 \mu \mathrm{m}$ diameters in sequence, micropolish, Buehler, Germany) on a water-saturated polishing pad (Microcloth, Buehler). The fabrication of $7 \times 11 \mathrm{~mm} \mathrm{TiN}$ working electrodes is described in our previous work. ${ }^{41}$

Thin Film Characterization. Scanning electron microscopy (SEM) was performed using a Zeiss EVO LS 25 with an accelerating voltage of $10 \mathrm{kV}$, and energy-dispersive $\mathrm{X}$-ray (EDX) data were obtained with an Oxford INCAx-act X-ray detector. EDX calibration was carried out using a $\mathrm{Bi}_{2} \mathrm{Te}_{3}$ powder standard (Strem Chemicals, 99.99\%). High-resolution SEM measurements were carried out with a field emission SEM (Jeol JSM 7500F) at an accelerating voltage of $2 \mathrm{kV}$. Xray diffraction (XRD) measurements were carried out using a Rigaku Smartlab diffractometer either in symmetric or in grazing incidence mode $\left(\theta_{1}=1^{\circ}\right)$ with a $9 \mathrm{~kW} \mathrm{Cu} \mathrm{K \alpha}(\lambda=$ $1.5418 \AA$ ) source, a parallel line focus incident beam, and a Hypix detector. Phase matching and lattice parameter refinement were carried out using the PDXL2 software package and diffraction patterns from the Inorganic Crystal Structure Database (ICSD). ${ }^{33}$ X-ray photoelectron spectroscopy (XPS) data were obtained using a ThermoScientific Theta Probe System with $\mathrm{Al}-\mathrm{K} \alpha$ radiation (photon energy = $1486.6 \mathrm{eV}$ ). XPS depth profiling was performed by using an Ar ion gun at a beam voltage of $3 \mathrm{kV}$ on a $2 \times 2 \mathrm{~mm}$ raster area.

The in-plane electrical conductivity $(\sigma)$ and Seebeck coefficient $(S)$ were simultaneously measured on a commercial JouleYacht Thin-film Thermoelectric Parameter Test System (MRS-3L). The system was calibrated using a nickel foil reference standard, and the measurement accuracy was found to be within $5 \%$ for resistivity and $7 \%$ for Seebeck coefficient measurements. The Hall coefficient $\left(R_{\mathrm{H}}\right)$ was determined at $300 \mathrm{~K}$ on a Nanometrics HL5500PC instrument using a van de Pauw configuration. The carrier concentration (n) and in-plane mobility $(\mu)$ were calculated according to $1 / n$ $=e R$ and $\mu=\sigma R$, respectively.

Thin Film Transfer. Target substrates of $1 \times 1 \mathrm{~cm}$ with 50 $\mathrm{nm}$ thick $\mathrm{SiO}_{2}$ were fabricated by dry thermal oxidation of a $\mathrm{Si}$ wafer in a Tempress Furnace tube. Twenty grams of polystyrene (Sigma-Aldrich, $M_{\mathrm{w}} \sim 280000$ by GPC) was dissolved in $100 \mathrm{~mL}$ of toluene (Fisher Chemical) to prepare $20 \mathrm{w} / \mathrm{v} \%$ solution. The solution was spin-coated on the $\mathrm{Bi}_{2} \mathrm{Te}_{3}$ thin films at $500 \mathrm{rpm}$ for $10 \mathrm{~s}$ followed by $1000 \mathrm{rpm}$ for $50 \mathrm{~s}$. The samples were then baked at $85{ }^{\circ} \mathrm{C}$ for $30 \mathrm{~min}$ to dry the polymer. A cut was made on the samples to allow solution to penetrate between the $\mathrm{Bi}_{2} \mathrm{Te}_{3}$ films coated with PS and the TiN substrates. The samples were then dipped into an AZ $400 \mathrm{~K}$ (Merck, $2 \% \mathrm{KOH}$ ) solution, which enables exfoliation of the $\mathrm{Bi}_{2} \mathrm{Te}_{3}$ films. Afterward, the films coated with the polymer were transferred onto $\mathrm{SiO}_{2}$ substrates and left to dry in air for 3 days to allow adhesion of the bismuth telluride films to the $\mathrm{SiO}_{2}$ substrates. Prior to the film transfer, the $\mathrm{SiO}_{2}$ substrates were activated by $\mathrm{O}_{2}$ plasma for $5 \mathrm{~min}$ in a Plasmalab 80 Plus (RIE) to improve adhesion of the transferred films. Finally, the carrier polymer was dissolved from $\mathrm{Bi}_{2} \mathrm{Te}_{3}$ films by dipping the samples in chloroform (Sigma-Aldrich, $\geq 99 \%$ ). The films were then dipped into acetone and isopropanol to remove the solvent (a schematic diagram of the transfer process can be found in Figure 5).

Optical microscopy (Nikon Eclipse LV150) and highresolution SEM (field emission SEM, Jeol JSM 7500F; an accelerating voltage of $2 \mathrm{kV}$ ) were used to characterize the films before and after the transfer.

\section{ASSOCIATED CONTENT}

\section{SI Supporting Information}

The Supporting Information is available free of charge at https://pubs.acs.org/doi/10.1021/acsomega.0c01284.

Cyclic voltammetry in an electrolyte containing 2.25 $\mathrm{mM}\left[\mathrm{N}^{n} \mathrm{Bu}_{4}\right]\left[\mathrm{BiCl}_{4}\right]$ and $3 \mathrm{mM}\left[\mathrm{N}^{n} \mathrm{Bu}_{4}\right]_{2}\left[\mathrm{TeCl}_{6}\right]$ (Section $\mathrm{S} 1$ ), image of a substrate with the electrodeposited bismuth telluride film (Section S2), and film thickness calculation (Section S3) (PDF)

\section{AUTHOR INFORMATION}

\section{Corresponding Author}

Katarina Cicvaric - School of Electronics and Computer Science, University of Southampton, Southampton SO17 1BJ, United Kingdom; 이이.org/0000-0002-1966-649X; Email: K.Cicvaric@soton.ac.uk

\section{Authors}

Lingcong Meng - School of Chemistry, University of Southampton, Southampton SO17 1BJ, United Kingdom

Daniel W. Newbrook - School of Electronics and Computer Science, University of Southampton, Southampton SO17 1BJ, United Kingdom

Ruomeng Huang - School of Electronics and Computer Science, University of Southampton, Southampton SO17 1BJ, United Kingdom; orcid.org/0000-0003-1185-635X

Sheng Ye - School of Electronics and Computer Science, University of Southampton, Southampton SO17 1BJ, United Kingdom

Wenjian Zhang - School of Chemistry, University of Southampton, Southampton SO17 1BJ, United Kingdom

Andrew L. Hector - School of Chemistry, University of Southampton, Southampton SO17 1BJ, United Kingdom; (1) orcid.org/0000-0002-9964-2163

Gillian Reid - School of Chemistry, University of Southampton, Southampton SO17 1BJ, United Kingdom; (1) orcid.org/00000001-5349-3468

Philip N. Bartlett - School of Chemistry, University of Southampton, Southampton SO17 1BJ, United Kingdom; (1) orcid.org/0000-0002-7300-6900

C. H. Kees de Groot - School of Electronics and Computer Science, University of Southampton, Southampton SO17 1BJ, United Kingdom; orcid.org/0000-0002-3850-7101

Complete contact information is available at:

https://pubs.acs.org/10.1021/acsomega.0c01284

\section{Notes}

The authors declare no competing financial interest.

\section{ACKNOWLEDGMENTS}

This work is part of the ADEPT (Advanced Devices by ElectroPlaTing) project funded by a Programme grant from the EPSRC (EP/N035437/1). The authors thank EPSRC for funding the Smartlab diffractometer under EP/K00509X/1 and EP/K009877/1. The authors also thank Dr. Jamie D. Reynolds for helpful advices about film transfer process. All data supporting this study are openly available from the University of Southampton repository at DOI: https:// doi.org/10.5258/SOTON/D1367. 


\section{REFERENCES}

(1) International Energy Outlook 2016, www.eia.gov/forecasts/ieo/ pdf/0484(2016).pdf, May 2016.

(2) Zhang, X.; Zhao, L.-D. Thermoelectric Materials: Energy Conversion between Heat and Electricity. J. Mater. 2015, 1, 92-105.

(3) Bell, L. E. Cooling, Heating, Generating Power, and Recovering Waste Heat with Thermoelectric Systems. Science. 2008, 321, 14571461.

(4) Tritt, T. M. Thermoelectric Phenomena, Materials, and Applications. Annu. Rev. Mater. Res. 2011, 41, 433-448.

(5) LeBlanc, S. Thermoelectric Generators: Linking Material Properties and Systems Engineering for Waste Heat Recovery Applications. Sustainable Mater. Technol. 2014, 1, 26-35.

(6) Chen, J.; Hu, H.; Wang, J.; Liu, C.; Liu, X.; Li, Z.; Chen, N. A dBand Electron Correlated Thermoelectric Thermistor Established in Metastable Perovskite Family of Rare-Earth Nickelates. ACS Appl. Mater. Interfaces 2019, 11, 34128-34134.

(7) Witting, I. T.; Chasapis, T. C.; Ricci, F.; Peters, M.; Heinz, N. A.; Hautier, G.; Snyder, G. J. The Thermoelectric Properties of Bismuth Telluride. Adv. Electron. Mater. 2019, 5, No. 201800904.

(8) Burton, M. R.; Richardson, S. J.; Staniec, P. A.; Terrill, N. J.; Elliott, J. M.; Squires, A. M.; White, N. M.; Nandhakumar, I. S. A Novel Route to Nanostructured Bismuth Telluride Films by Electrodeposition. Electrochem. Commun. 2017, 76, 71-74.

(9) Li, X.; Koukharenko, E.; Nandhakumar, I. S.; Tudor, J.; Beeby, S. P.; White, N. M. High Density p-Type $\mathrm{Bi}_{0.5} \mathrm{Sb}_{1.5} \mathrm{Te}_{3}$ Nanowires by Electrochemical Templating through Ion-Track Lithography. Phys. Chem. Chem. Phys. 2009, 11, 3584-3590.

(10) Martín, J.; Manzano, C. V.; Caballero-Calero, O.; MartinGonzalez, M. High-Aspect-Ratio and Highly Ordered 15-nm Porous Alumina Templates. ACS Appl. Mater. Interfaces 2013, 5, 72-79.

(11) Yoo, I. J.; Myung, N. V.; Lim, D. C.; Song, Y.; Jeong, Y. K.; Kim, Y.; Do; Lee, K. H.; Lim, J. H. Electrodeposition of $\mathrm{Bi}_{\mathrm{x}} \mathrm{Te}_{\mathrm{y}} \mathrm{Thin}$ Films for Thermoelectric Application. Thin Solid Films 2013, 546, $48-52$.

(12) Heo, P.; Hagiwara, K.; Ichino, R.; Okido, M. Electrodeposition and Thermoelectric Characterization of $\mathrm{Bi}_{2} \mathrm{Te}_{3}$. J. Electrochem. Soc. 2006, 153, C213.

(13) Kang, W. S.; Li, W. J.; Chou, W. C.; Tseng, M. F.; Lin, C. S. Microstructure and Thermoelectric Properties of $\mathrm{Bi}_{2} \mathrm{Te}_{3}$ Electrodeposits Plated in Nitric and Hydrochloric Acid Baths. Thin Solid Films 2017, 623, 90-97.

(14) Jiang, Q.; Liu, C.; Song, H.; Xu, J.; Mo, D.; Shi, H.; Wang, Z.; Jiang, F.; Lu, B.; Zhu, Z. Free-Standing PEDOT: PSS Film as Electrode for the Electrodeposition of Bismuth Telluride and Its Thermoelectric Performance. Int. J. Electrochem. Sci. 2014, 9, 75407551.

(15) Matsuoka, K.; Okuhata, M.; Hatsuta, N.; Takashiri, M. Effect of Composition on the Properties of Bismuth Telluride Thin Films Produced by Galvanostatic Electrodeposition. Trans. Mater. Res. Soc. Jpn. 2015, 40, 383-387.

(16) Yoo, B. Y.; Huang, C. K.; Lim, J. R.; Herman, J.; Ryan, M. A.; Fleurial, J. P.; Myung, N. V. Electrochemically Deposited Thermoelectric n-Type $\mathrm{Bi}_{2} \mathrm{Te}_{3}$ Thin Films. Electrochim. Acta 2005, 50, 43714377.

(17) Takashiri, M.; Makioka, T.; Yamamuro, H. Promotion of Crystal Growth in as-Grown $\mathrm{Bi}_{2} \mathrm{Te}_{3}$ Electrodeposited Films without Micro-Pores Using Sputtered $\mathrm{Bi}_{2} \mathrm{Te}_{3}$ Seed Layers Deposited on a Glass Substrate. J. Alloys Compd. 2018, 764, 802-808.

(18) Ma, Y.; Ahlberg, E.; Sun, Y.; Iversen, B. B.; Palmqvist, A. E. C. Thermoelectric Properties of Thin Films of Bismuth Telluride Electrochemically Deposited on Stainless Steel Substrates. Electrochim. Acta 2011, 56, 4216-4223.

(19) Manzano, C. V.; Rojas, A. A.; Decepida, M.; Abad, B.; Feliz, Y.; Caballero-Calero, O.; Borca-Tasciuc, D. A.; Martin-Gonzalez, M. Thermoelectric Properties of $\mathrm{Bi}_{2} \mathrm{Te}_{3}$ Films by Constant and Pulsed Electrodeposition. J. Solid State Electrochem. 2013, 17, 2071-2078.

(20) Zhou, A.; Fu, Q.; Zhang, W.; Yang, B.; Li, J.; Ziolkowski, P.; Mueller, E.; Xu, D. Enhancing the Thermoelectric Properties of the
Electroplated $\mathrm{Bi}_{2} \mathrm{Te}_{3}$ Films by Tuning the Pulse Off-to-on Ratio. Electrochim. Acta 2015, 178, 217-224.

(21) Manzano, C. V.; Abad, B.; Muñoz Rojo, M.; Koh, Y. R.; Hodson, S. L.; Lopez Martinez, A. M.; Xu, X.; Shakouri, A.; Sands, T. D.; Borca-Tasciuc, T.; Martin-Gonzalez, M. Anisotropic Effects on the Thermoelectric Properties of Highly Oriented Electrodeposited $\mathrm{Bi}_{2} \mathrm{Te}_{3}$ Films. Sci. Rep. 2016, 6, No. 19129.

(22) Abellán, M.; Schrebler, R.; Gómez, H. Electrodeposition of $\mathrm{Bi}_{2} \mathrm{Te}_{3}$ Thin Films onto FTO Substrates from DMSO Solution. Int. J. Electrochem. Sci. 2015, 10, 7409-7422.

(23) Nguyen, H. P.; Wu, M.; Su, J.; Vullers, R. J. M.; Vereecken, P. M.; Fransaer, J. Electrodeposition of Bismuth Telluride Thermoelectric Films from a Nonaqueous Electrolyte Using Ethylene Glycol. Electrochim. Acta 2012, 68, 9-17.

(24) Wu, M.; Nguyen, H. P.; Vullers, R. J. M.; Vereecken, P. M.; Binnemans, K.; Fransaer, J. Electrodeposition of Bismuth Telluride Thermoelectric Films from Chloride-Free Ethylene Glycol Solutions. J. Electrochem. Soc. 2013, 160, D196-D201.

(25) Szymczak, J.; Legeai, S.; Michel, S.; Diliberto, S.; Stein, N.; Boulanger, C. Electrodeposition of Stoichiometric Bismuth Telluride $\mathrm{Bi}_{2} \mathrm{Te}_{3}$ Using a Piperidinium Ionic Liquid Binary Mixture. Electrochim. Acta 2014, 137, 586-594.

(26) Meng, L.; Cicvarić, K.; Hector, A. L.; de Groot, C. H.; Bartlett, P. N. Electrodeposition of Bismuth Telluride from a Weakly Coordinating, Non-Aqueous Solution. J. Electroanal. Chem. 2019, 839, 134-140.

(27) Bansal, N.; Cho, M. R.; Brahlek, M.; Koirala, N.; Horibe, Y.; Chen, J.; Wu, W.; Park, Y. D.; Oh, S. Transferring MBE-Grown Topological Insulator Films to Arbitrary Substrates and MetalInsulator Transition via Dirac Gap. Nano Lett. 2014, 14, 1343-1348.

(28) Yu, Y.; Fong, P. W. K.; Wang, S.; Surya, C. Fabrication of $\mathrm{WS}_{2} /$ GaN P-N Junction by Wafer-Scale WS $\mathrm{W}_{2}$ Thin Film Transfer. Sci. Rep. 2016, 6, No. 37833.

(29) Burton, M. R.; Naylor, A. J.; Nandhakumar, I. S. Electrochemically Copper-Doped Bismuth Tellurium Selenide Thin Films. Electrochem. Commun. 2018, 97, 56-59.

(30) Lei, C.; Burton, M. R.; Nandhakumar, I. S. Facile Production of Thermoelectric Bismuth Telluride Thick Films in the Presence of Polyvinyl Alcohol. Phys. Chem. Chem. Phys. 2016, 18, 14164-14167.

(31) Takahashi, M.; Kojima, M.; Sato, S. Electric and Thermoelectric Properties of Electrodeposited Bismuth Telluride $\left(\mathrm{Bi}_{2} \mathrm{Te}_{3}\right)$ Films. J. Appl. Phys. 2004, 96, 5582.

(32) Rasband, W. S. ImageJ, U. S. National Institutes of Health, Bethesda, Maryland, USA, 1997-2018. https://imagej.nih.gov/ij/.

(33) Inorganic Crystal Structure Database (ICSD, Fiz Karlsruhe, Germany) Accessed via the National Chemical Database Service Hosted by the Royal Society of Chemistry.

(34) Bando, H.; Koizumi, K.; Oikawa, Y.; Daikohara, K.; Kulbachinskii, V. A.; Ozaki, H. The Time-Dependent Process of Oxidation of the Surface of $\mathrm{Bi}_{2} \mathrm{Te}_{3}$ Studied by X-Ray Photoelectron Spectroscopy. J. Phys.: Condens. Matter 2000, 12, 5607-5616.

(35) Zhao, Y.; Burda, C. Chemical Synthesis of $\mathrm{Bi}_{0.5} \mathrm{Sb}_{1.5} \mathrm{Te}_{3}$ Nanocrystals and Their Surface Oxidation Properties. ACS Appl. Mater. Interfaces 2009, 1, 1259-1263.

(36) Patil, S. M.; Mane, S. R.; Mane, R. M.; Mali, S. S.; Patil, P. S.; Bhosale, P. N. Synthesis and X-Ray Photoelectron Spectroscopy (XPS) and Thermoelectric Studies of Ternary $\mathrm{Bi}_{2}\left(\mathrm{Te}_{0.5} \mathrm{Se}_{0.5}\right)_{3}$ MixedMetal Chalcogenide Thin Films by the Arrested Precipitation Technique. Can. J. Chem. 2011, 89, 1375-1381.

(37) Ingersoll, D.; Lima-Sharma, A. L.; Adams, D. P.; Sharma, P. A.; Lu, P.; Ihlefeld, J. F.; Michael, J. R.; Chou, S.; Sugar, J. D.; Brumbach, M. Electrical Contact Uniformity and Surface Oxidation of Ternary Chalcogenide Alloys. AIP Adv. 2019, 9, 15125.

(38) Music, D.; Chang, K.; Schmidt, P.; Braun, F. N.; Heller, M.; Hermsen, S.; Pöllmann, P. J.; Schulzendorff, T.; Wagner, C. On Atomic Mechanisms Governing the Oxidation of $\mathrm{Bi}_{2} \mathrm{Te}_{3}$. J. Phys.: Condens. Matter 2017, 29, No. 485705.

(39) Yashina, L. V.; Sánchez-Barriga, J.; Scholz, M. R.; Volykhov, A. A.; Sirotina, A. P.; Neudachina, V. S.; Tamm, M. E.; Varykhalov, A.; 
Marchenko, D.; Springholz, G.; Bauer, G.; Knop-Gericke, A.; Rader, O. Negligible Surface Reactivity of Topological Insulators $\mathrm{Bi}_{2} \mathrm{Se}_{3}$ and $\mathrm{Bi}_{2} \mathrm{Te}_{3}$ towards Oxygen and Water. ACS Nano 2013, 7, 5181-5191.

(40) Caballero-Calero, O.; Díaz-Chao, P.; Abad, B.; Manzano, C. V.; Ynsa, M. D.; Romero, J. J.; Rojo, M. M.; Martín-González, M. S. Improvement of Bismuth Telluride Electrodeposited Films by the Addition of Sodium Lignosulfonate. Electrochim. Acta 2014, 123, $117-126$.

(41) Bartlett, P. N.; Cook, D.; De Groot, C. H.; Hector, A. L.; Huang, R.; Jolleys, A.; Kissling, G. P.; Levason, W.; Pearce, S. J.; Reid, G. Non-Aqueous Electrodeposition of P-Block Metals and Metalloids from Halometallate Salts. RSC Adv. 2013, 3, 15645-15654. 